Review Article

\title{
Angiotensin receptor/neprilysin inhibitor: a novel therapy in the treatment of heart failure
}

\author{
Rohini Gupta*, Pavan Malhotra, Diwanshu Sharma
}

Department of Pharmacology and Therapeutics, SC College of Medical Sciences and Hospital, Sidhra, Jammu, India

Received: 31 May 2016

Accepted: 01 July 2016

\section{*Correspondence to:}

Dr. Rohini Gupta,

Email: rohinigupta299@ gmail.com

Copyright: (C) the author(s), publisher and licensee Medip Academy. This is an openaccess article distributed under the terms of the Creative Commons Attribution NonCommercial License, which permits unrestricted noncommercial use, distribution, and reproduction in any medium, provided the original work is properly cited.

\begin{abstract}
Recently US Food and Drug Administration (FDA) approved valsartan/sacubitril is the first angiotensin receptor/neprilysin inhibitor (ARNI) that offers a new standard of treatment to physicians for the patients of heart failure with reduced ejection fraction. Sacubitril is a prodrug which gets activated to sacubitrilat and this inhibits the enzyme neprilysin which is a membrane bound endopeptidase and which in turn is responsible for the degradation of various natriuretic peptides. The action of Valsartan which selectively blocks the angiotensin II type-1 receptor is needed in addition to sacubitril because inhibition of neprilysin is accompanied by the activation of renin-angiotensin system. The combination appears to be a suitable alternative for patients of heart failure with persistent symptoms or with recent exacerbation or hospitalization while on standard optimized treatment. The availability of this novel sacubitril/valsartan combination is an important development in the heart failure management.
\end{abstract}

Keywords: Neprilysin, Sacubitril/valsartan, Heart failure, ARNI

\section{INTRODUCTION}

Heart failure, often referred to as congestive heart failure, is a pathophysiologic state in which the heart is unable to pump blood at a rate which commensurate with the requirements of metabolizing tissue, or can do so only from an elevated filling pressure. ${ }^{1}$ This results in a clinical syndrome of decreased exercise tolerance with pulmonary and systemic venous congestion. ${ }^{2}$ The common causes of heart failure include coronary artery disease, diabetes, obesity and hypertension. ${ }^{3}$

Ejection fraction is a key measurement in assessing the heart's ability to pump out blood and in diagnosing and monitoring heart failure. A substantial number of patients with heart failure have a normal ejection fraction. A preserved ejection fraction (i.e., diastolic heart failure) indicates that the heart muscle contracts normally, but the ventricles do not relax as they should; a reduced ejection fraction (i.e., systolic heart failure) indicates that the heart muscle does not contract effectively and less oxygen-rich blood is pumped out from the heart. ${ }^{4}$

Heart failure represents a main cause of morbidity and mortality and the first reason for hospital admission in older people, approximately $50 \%$ of patients with heart failure die within 5 years of diagnosis.,

\section{Pharmacotherapy of heart failure}

The developments in the treatment of heart failure over the past decades in terms of drug therapy have resulted in a significant improvement in the morbidity pattern of chronic heart failure. The cornerstone of modern drug therapy in chronic heart failure is the inhibition of neurohumoral activation. More specifically, the drug therapy 
aims at inhibition of the renin-angiotensin-aldosterone system and the sympathetic nervous system. Both of these systems play a crucial role in the pathophysiology of heart failure development and progression. The drug therapy in heart failure has been proven beneficial for patients with reduced ejection fraction but the same is not true for those with preserved ejection fraction, who roughly represent half of the total heart failure population. $^{7}$

Among the various groups of drugs used in patients with heart failure, angiotensin converting enzyme (ACE) inhibitors prolong survival in patients with reduced ejection fraction (HFrEF) and have served as the backbone of heart failure management for over two decades. ${ }^{8}$

\section{Natriuretic peptides}

Natriuretic peptides (NPs) are the hormones responsible for maintaining sodium and fluid homeostasis; their release is triggered by increased myocardial filling pressures. Benefits of NPs include direct vasodilation, increased glomerular filtration rate and reduced release of renin from the kidneys, in addition to natriuresis and diuresis. ${ }^{9}$

\section{Neprilysin inhibition}

Neprilysin is a membrane-bound endopeptidase found in many tissues, particularly in the kidney. ${ }^{10,11}$ It hydrolyses atrial natriuretic peptide (ANP), brain natriuretic peptide (BNP) and C-type natriuretic peptide (and possibly urodilatin). ${ }^{12-14}$ Neprilysin has been called by many other names, including enkephalinase, neutral endopeptidase, vasopeptidase and atriopeptidase. ${ }^{10-15}$ Degradation by neprilysin is one of the two major means of elimination of natriuretic peptides, the other being through a clearance receptor (the natriuretic peptide clearance receptor; NPRC or NPR3). ${ }^{16}$ Inhibition of neprilysin, therefore, represents a major approach in enhancing endogenous natriuretic peptide levels and activity.

Neprilysin, which has been described as a 'promiscuous' enzyme, also breaks down angiotensin II. ${ }^{17}$ Consequently, by increasing levels of this peptide, neprilysin inhibition may cause vasoconstriction, offsetting the vasodilator actions of augmented natriuretic peptides. Hence, neprilysin inhibitor must be combined with an inhibitor of the rennin-angiotensin-aldosterone (RAAS) system. Thus combining a neprilysin inhibitor and an angiotensin receptor blocker would prolong the survival of patients with heart failure with decreased ejection fraction.

There are three primary issues that must be considered when treating heart failure patients with reduced left ventricular ejection fraction (LVEF):

- Improving symptoms and quality of life,
- Slowing the progression or reversing cardiac and peripheral dysfunction, and

- Reducing mortality.

\section{Angiotensin receptor/neprilysin inhibitor (ARNI) in HFrEF}

On July 7, 2015, the US FDA approved neprilysin inhibitor sacubitril combined with an angiotensin receptor blocker valsartan (brand name Entresto/LCZ696) to reduce the risk for cardiovascular death and hospitalization in patients with chronic heart failure (NYHA class II-IV) associated with reduced ejection fraction.18 Valsartan was initially approved by the FDA in 1996 for the treatment of hypertension and in 2002 for the treatment of heart failure. In 2005, valsartan received FDA approval to reduce cardiovascular mortality in clinically stable patients with left ventricular (LV) failure or with LV dysfunction after a myocardial infarction. ${ }^{19}$

Sacubitril inhibits neprilysin and thus helps to improve many of the pathophysiological abnormalities of heart failure. $^{20}$ In patients with heart failure, neprilysin may actually have increased activity, so blocking it with valsartan/sacubitril combination may provide even more favorable results to these patients. ${ }^{21}$ Valsartan selectively blocks the angiotensin II type-1 receptor and inhibits the release of angiotensin II-dependent aldosterone. ${ }^{20}$ This action is needed in addition to sacubitril because inhibition of neprilysin is accompanied by the activation of the renin-angiotensin system. This combination of valsartan and sacubitril is described as an angiotensin receptor-neprilysin inhibitor (ARNI). ${ }^{21}$ The mechanism of action of sacubitril/valsartan is shown in Figure 1.

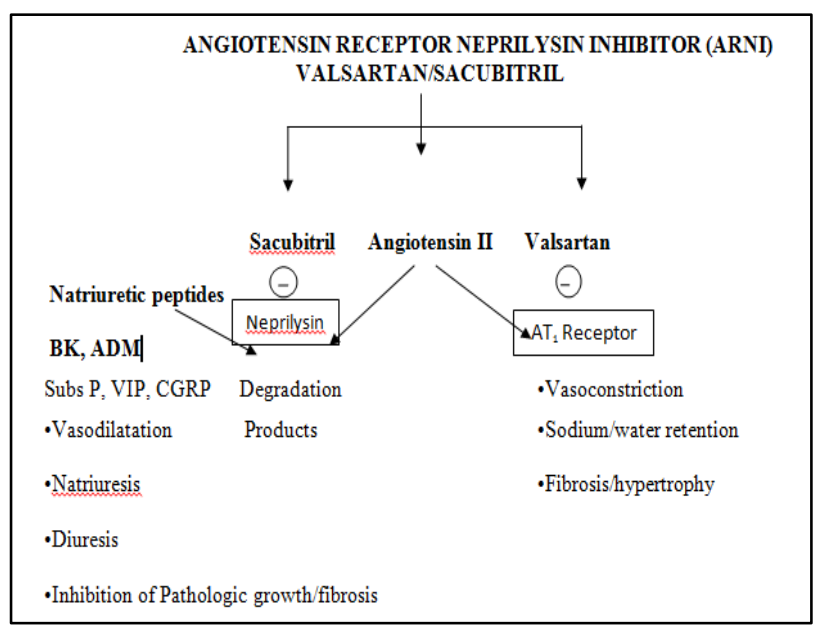

Figure 1: Mechanism of action of LCZ696 (sacubitril valsartan). ADM, adrenomedullin; AT1, angiotensin II type 1; BK, bradykinin; CGRP, calcitonin generelated peptide; Subs-P, substance P; VIP, vasoactive intestinal (poly)peptide. For possible sacubitril substrates, larger font size indicates greater evidence for such an effect in humans. 


\section{Adverse effects}

The most commonly reported adverse reactions with valsartan/sacubitril combination are hypotension, hyperkalemia, cough, dizziness, and renal failure. valsartan/sacubitril should not be given with ACE inhibitors (e.g., enalapril), renin inhibitor (e.g., aliskiren), or with another angiotensin receptor blocker (ARB). valsartan/sacubitril if given along with ACE inhibitors increase the risk of angioedema. Using valsartan/sacubitril with potassium-sparing diuretics, potassium supplements or with salt substitutes can lead to increase in the serum potassium levels. Combining valsartan/sacubitril with NSAIDs may increase the risk of renal impairment. Concomitant use of valsartan/sacubitril combination with lithium leads to an increased risk of lithium toxicity. ${ }^{20}$

\section{Contraindications}

Valsartan/sacubitril combination is contraindicated in all such patients with a history of angioedema due to previous exposure to ACE inhibitor or $\mathrm{ARB}$ and in patients with diabetes. Patients on Valsartan/sacubitril combination should be closely monitored for signs and symptoms of angioedema and hypotension. Renal function and serum potassium levels should be monitored periodically. It is not recommended in patients with severe hepatic impairment. ${ }^{20}$

\section{Pregnancy and lactation}

There is no information on the use of valsartan/sacubitril in lactating women, so presumably it is not recommended. Valsartan/sacubitril can cause fetal harm when administered to pregnant women therefore it is not recommended. The use of drugs that act on the reninangiotensin system, such as valsartan/sacubitril combination, during the second and third trimesters of pregnancy can reduce fetal renal function and increase fetal and neonatal morbidity and death. If a patient becomes pregnant while taking valsartan/sacubitril, the drug should be discontinued with immediate effect to prevent any teratogenic effect. ${ }^{20}$

\section{CONCLUSION}

Valsartan/sacubitril combination is a new option for the treatment of patients with reduced ejection fraction heart failure. It has been shown to be effective in the treatment of systolic heart failure, preventing one more cardiovascular death or heart failure hospital admission for every 21 patients treated for two years, compared to Enalapril. It has also been shown to decrease the all-cause mortality and reduce the symptoms of heart failure.

Standard heart failure therapy with optimal doses should still be recommended as first-line treatment in most patients with systolic heart failure. If there are persistent symptoms, with recent exacerbations or hospitalization while on this optimized treatment, consider changing the ACE inhibitor or ARB to valsartan/sacubitril combination. This drug is not indicated for patients with preserved ejection fraction. $^{22}$

Funding: No funding sources

Conflict of interest: None declared

Ethical approval: None required

\section{REFERENCES}

1. Braunwald E, Bristow MR. Congestive heart failure: fifty years of progress. Circulation. 2000;102(Suppl IV):14-23.

2. Maron BA, Rocco TP. Pharmacotherapy of congestive heart failure. Section III: modulation of cardiovascular function. In: Bruton LL, Chabner BA, Knollmann BC (editors), Goodman and Gilman's The Pharmacological Basis of Therapeutics, $12^{\text {th }}$ edition. New York: McGraw-Hill Co; 2012:754-75.

3. Mayo clinic staff. Diseases and conditions: heart failure, 2015. Available at www.mayoclinic.org/diseases-conditions/heartfailure/basics/definition/con-20029801.

4. American Heart Association. Ejection fraction heart failure measurement, 2015. Available at www.heart.org/HEARTORG/Conditions/HeartFailur e/Symptoms DiagnosisofHeartFailure/EjectionFraction-Heart-Failure-Measurement_UCM_ 306339_Article.jsp\#.

5. Gheorghiade M, Filippatos G, Felker GM. Diagnosis and management of acute heart failure syndromes. In: Mann DL, Zipes DP, Libby P, Bonow RO (editors), Braunwald's heart disease: a textbook of cardiovascular medicine, $9^{\text {th }}$ edition. Philadelphia: Elsevier; 2012:517-42.

6. Centers for disease control and prevention. Heart failure fact sheet, 2013. Available at www.cdc.gov/dhdsp/data_statistics/fact_sheets/fs_he art_failure.htm.

7. McMurray JJ, Adamopoulos S, Anker SD, Auricchio A, Bohm M, Dickstein K, et al. ESC committee for practice guidelines. ESC guidelines for the diagnosis and treatment of acute and chronic heart failure 2012: the task force for the diagnosis and treatment of acute and chronic heart failure 2012 of the European Society of Cardiology. Developed in collaboration with the Heart Failure Association (HFA) of the ESC. Eur Heart J. 2012;33:1787-847.

8. Yancy CW, Jessup M, Bozkurt B. ACCF/AHA guideline for the management of heart failure: a report of the American College of Cardiology Foundation/American Heart Association Task Force on practice guidelines. Circulation. 2013;128:181052.

9. Vardeny O, Miller R, Solomon SD. Combined neprilysin and renin-angiotensin system inhibition for the treatment of heart failure. JACC Heart Fail. 2014;2:663-70. 
10. Matsas R, Fulcher IS, Kenny AJ, Turner AJ. Substance $\mathrm{P}$ and Leuenkephalin are hydrolyzed by an enzyme in pig caudate synaptic membranes that is identical with the endopeptidase of kidney microvilli. Proc Natl Acad Sci USA. 1983;80:3111-5.

11. Vanneste Y, Michel A, Dimaline R, Najdovski T, Deschodt-Lanckman M. Hydrolysis of alpha-human atrial natriuretic peptide in vitro by human kidney membranes and purified endopeptidase-24.11. Evidence for a novel cleavage site. Biochem J. 1988;254:531-7.

12. Lang CC, Motwani JG, Coutie WJ, Struthers AD. Clearance of brain natriuretic peptide in patients with chronic heart failure: indirect evidence for a neutral endopeptidase mechanism but against an atrial natriuretic peptide clearance receptor mechanism. Clin Sci (Lond). 1992;82:619-23.

13. Abassi ZA, Golomb E, Agbaria R, Roller PP, Tate J, Keiser HR. Hydrolysis of iodine labelled urodilatin and ANP by recombinant neutral endopeptidase EC. Br J Pharmacol. 1994;113:204-8.

14. Brandt RR, Mattingly MT, Clavell AL, Barclay PL, Burnett JC. Neutral endopeptidase regulates C-type natriuretic peptide metabolism but does not potentiate its bioactivity in vivo. Hypertension. 1997;30:184-90.

15. Cha YM, Dzeja PP, Redfield MM, Shen WK, Terzic A. Bioenergetic protection of failing atrial and ventricular myocardium by vasopeptidase inhibitor omapatrilat. Am J Physiol Heart Circ Physiol. 2006;290:H1686-92.

16. Clerico A, Iervasi G. Alterations in metabolic clearance of atrial natriuretic peptides in heart failure: how do they relate to the resistance to atrial natriuretic peptides? J Card Fail. 1995;1:323-8.

17. Dalzell JR, Seed A, Berry C, Whelan CJ, Petrie MC, Padmanabhan $\mathrm{N}$, et al. Effects of neutral endopeptidase (neprilysin) inhibition on the response to other vasoactive peptides in small human resistance arteries: Studies with thiorphan and omapatrilat. Cardiovasc Ther. 2014;32:13-8.

18. US Food and Drug Administration. FDA approves new drug to treat heart failure. Press release, 2015. Available www.fda.gov/NewsEvents/Newsroom/Press. Announcements/ucm453845.htm.

19. US Food and Drug Administration. Diovan new indication approval letter; 2005. Available at www.accessdata.fda.gov/drugsatfda_docs/appletter/2 005/021283s011ltr.pdf.

20. Product information for Entresto. Novartis Pharmaceuticals Co. East Hanover, NJ 07936, 2015. Available at https://www.pharma.us.novartis.com/sites/www.phar ma.us.novartis.com/files/entresto.pdf.

21. Packer M, McMurray JJ, Desai AS, Gong J, Lefkowitz MP, Rizkala AR, et al. Angiotensin receptor neprilysin inhibition compared with enalapril on the risk of clinical progression in surviving patients with heart failure. Circulation. 2015;131:54-61.

22. McMurray JJ, Packer M, Desai AS, Gong J, Lefkowitz MP, Rizkala AR, et al. Angiotensionneprilysin inhibition versus enalapril in heart failure. N Engl J Med. 2014;371:993-1004.

Cite this article as: Gupta R, Malhotra P, Sharma D. Angiotensin receptor/neprilysin inhibitor: a novel therapy in the treatment of heart failure. Int $\mathrm{J}$ Basic Clin Pharmacol 2016;5:1175-8. 